\title{
Alizarine Yellow $R$ as Reagent of the Determination of Manganese by Extraction-Photometric Method
}

\author{
G. G. Abbasova, A. M. Pashajanov \\ ANAS Institute of Catalysis and Inorganic Chemistry Named after Acad. M. Naghiyev, Baki, Azerbaijan \\ Email: veliyeva_g@mail.ru
}

How to cite this paper: Abbasova, G.G. and Pashajanov, A.M. (2018) Alizarine Yellow $\mathrm{R}$ as Reagent of the Determination of Manganese by Extraction-Photometric Method. Journal of Materials Science and Chemical Engineering, 6, 12-18. https://doi.org/10.4236/msce.2018.610002

Received: August 29, 2018

Accepted: October 21, 2018

Published: October 25, 2018

Copyright $\odot 2018$ by authors and Scientific Research Publishing Inc. This work is licensed under the Creative Commons Attribution International License (CC BY 4.0).

http://creativecommons.org/licenses/by/4.0/

\begin{abstract}
4,7-diphenyl-1,10-phenantroline from heterocyclic diamines and alizarine yellow R from chromogenic reagents have been used for spectrophotometric determination of manganese in the form of heteroligand manganese complex. The complex formation and extraction condition, physical-chemical and analytical characteristics of this complex have been established. $5.5-11.0 \mathrm{pH}$ range is observed as complex formation $\mathrm{pH}$ range. Extraction and stability constants were accordingly found as $\mathrm{K}_{\text {ext }}=8.32 \times 10^{14}$ and $\lg \beta_{\mathrm{K}}=7.2 \pm 0.1$. Molar absorptivity is $\mathcal{E}=(2.27 \pm 0.08) \times 10^{4} \mathrm{l} \cdot \mathrm{g}^{-1} \cdot \mathrm{cm}^{-1}$. In the range of 0.5 $23.0 \mu \mathrm{kg}$ manganese (II) Beer's law is obeyed. The extraction-photometric methods of manganese determination have been worked out. The strangers ions influence on determination of manganese (II) has been studied. To determine amount of manganese in eggplant the proposed method was applied successfully.
\end{abstract}

\section{Keywords}

Extraction-Photometric Determination, Complexing, Manganese,

4,7-Diphenyl-1,10-phenantroline, Alizarine Yellow R

\section{Introduction}

Manganese is a trace element essential for living organisms include plants as a nutrient participates in photosynthesis, enzyme activation, carbohydrate metabolism and phosphorylation [1].

Besides of this manganese is used as a very important hardening agent in steel industry. That's why it often requires to determinate the amount of manganese in chemical, biological and environmental samples. 
There are different methods for the determination of manganese which have been reported for the latest. Range of suggesting reagents for determination of manganese is very widely. For instant, the latest investigations include reagents such as picolinaldehyde nicotinoyl hydrazone [2], o-hydroxythiophenol derivatives and aminophenols [3], 2-hydroxy-4-methoxy acetophenone oxime (HMAO) [4].

In the literature there are various experimental data about using of derivatives of azosalicylic acid for determination of manganese.

As we know the stability constant of $\mathrm{Mn}$ (II) complexes are lower than those of other metals, which is in accordance with the Irving-Williams order [5]. As the result of it spectrophotometric determination methods of manganese in the form of inorganic compounds are less. In the present investigation for this reason the heteroligand complex of manganese with 4,7-diphenyl-1,10-phenantroline (BPhen) from heterocyclic diamines and with alizarine yellow R (AlR) from chromogenic organic reagents and the new rapid, simple and sensitive extraction-photometric method of manganese determination with this reagents is reported.

\section{Experimental}

\subsection{Apparatus and Reagents}

Absorption measurements were collected on a CФ 46 "LOMO" spectrophotometer or КФК-3 photoelectrocolourymeter using $1 \mathrm{~cm}$ cells. The $\mathrm{pH}$-meter $\mathrm{EV}-74$ is used for $\mathrm{pH}$ measurements.

Stock solution of $1.52 \times 10^{-2} \mathrm{M}$ manganese (II) was prepared from $\mathrm{MnCl}_{2} \cdot 4 \mathrm{H}_{2} \mathrm{O}$ salt with qualification "p.f.a." (pure for analysis) and quantity of manganese standardized gravimetrically with o-phenantroline and SCN- [6]. Working solution of $4.5 \times 10^{-4} \mathrm{M}$ manganese (II) was prepared by dilution of stock solution with deionized water. Solution of AlR with $5 \times 10^{-3} \mathrm{M}$ concentration was prepared by dissolving the required amount in water, while $\mathrm{pH}$ of this water was arrived to 12 , preliminarily. Because, $\mathrm{pK}_{1}=2.65$ and $\mathrm{pK}_{2}=11.78$ for AlR [7]. Solution of BPhen with $6.0 \times 10^{-3} \mathrm{M}$ concentration was prepared by dissolving the required amount of preparate which was productioned in the University of Lvovby order of "Soyuzreaktiv" in ethanol: water (50:50, by volume). Universal or borate buffer solutions $\left(\mathrm{H}_{3} \mathrm{BO}_{3}+\mathrm{HCl}, \mathrm{H}_{3} \mathrm{BO}_{3}+\mathrm{NaOH}\right)$ or $0.1 \mathrm{M} \mathrm{CH} 3 \mathrm{COOH}$ and $1 \mathrm{NNaOH}$ solutions were used for obtaining appropriate $\mathrm{pH}$.

\subsection{Experiment Procedure}

Suitable amount of solutions of BPhen and AlR have been added to the definite amount of solution of manganese (II) in test-tube with stoppers or in separatory funnel. Then all out of volume have been diluted to $10 \mathrm{ml}$ by adding of various (pH 5.0 - 11.0) buffer solution. The mixture has been trembled for a minute with adding of $5 \mathrm{ml}$ solvent (chloroform). Then colored extract has been transferred to the cells, when the phases separated and absorbance has been measured relative to the water. The same experiment has been carried out without manganese 
and absorbance of the extract of reagent has been measured also relative to the water.

\section{Results and Discussion}

\subsection{Condition of Complexing and Spectral Characteristics}

The absorption spectra of AlR and complex of manganese with BPhen and AlR obtained in the $\mathrm{pH}$ range $5.5-11.0$ of the aqueous phase showed that manganese (II) with BPhen and AlR forms a complex one composition. The absorption spectra of solutions of reagent and the complex show that the maximum absorbance takes place at $\mathrm{pH} 8.3$ (Figure 1) and wavelengths of 390 and $370 \mathrm{~nm}$, respectively in extract and reagent have been selected for the present work (Figure 2).

The influence of the concentration of BPhen and AlR was studied. The optimal concentration of BPhen and AlR for formation of the complex was found to be $9.0 \times 10^{-5} \mathrm{M}$ and $4.5 \times 10^{-4} \mathrm{M}$, respectively. Extra quantity of reagents doesn't affect the formation and extraction of the complex. As, the carboxyl group of the chromogenic organic reagent in the condition of complexing is ionized and charged form is preferably in the aqueous phase. The heteroligand complex of manganese (II) with BPhen and AlR was extracted with chloroform and 1,2-dichloroethane. Optimal volume of aqueous and organic phase was found to be 25 - 50 and $5 \mathrm{ml}$, respectively. Mn-BPhen-AlR complex is formed immediately after adding the reagents and extraction equilibrium is achieved by trembling 1 minute. The sequence of reagents to be added does not influence the complex formation and extraction. The intensity of color of the complex does not change depending on time and stable during the day.

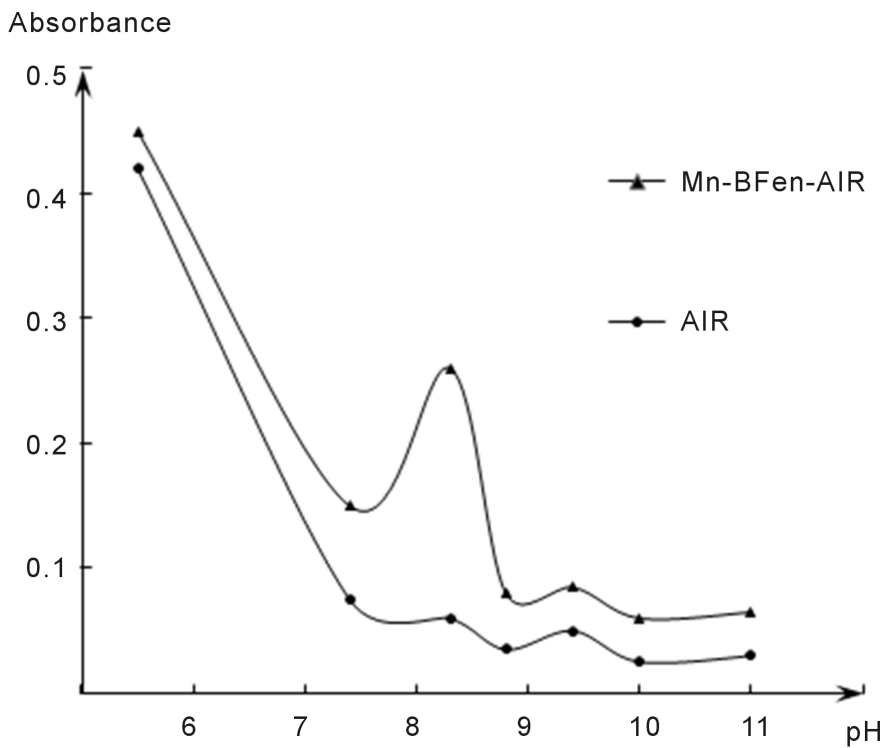

Figure 1. Influence of $\mathrm{pH}$ of the aqueous phase in the formation and extraction of the complex of manganese (II) with BPhen and A1R $\left(\mathrm{Mn}^{+2}=2.23 \times 10^{-5} \mathrm{M}, \mathrm{C}_{\mathrm{BPhen}}=1.2 \times\right.$ $\left.10^{-4} \mathrm{M}, \mathrm{C}_{\mathrm{A} 1 \mathrm{R}}=1.5 \times 10^{-4} \mathrm{M}, \mathrm{KFK}-3, \lambda=400 \mathrm{~nm}\right)$. 


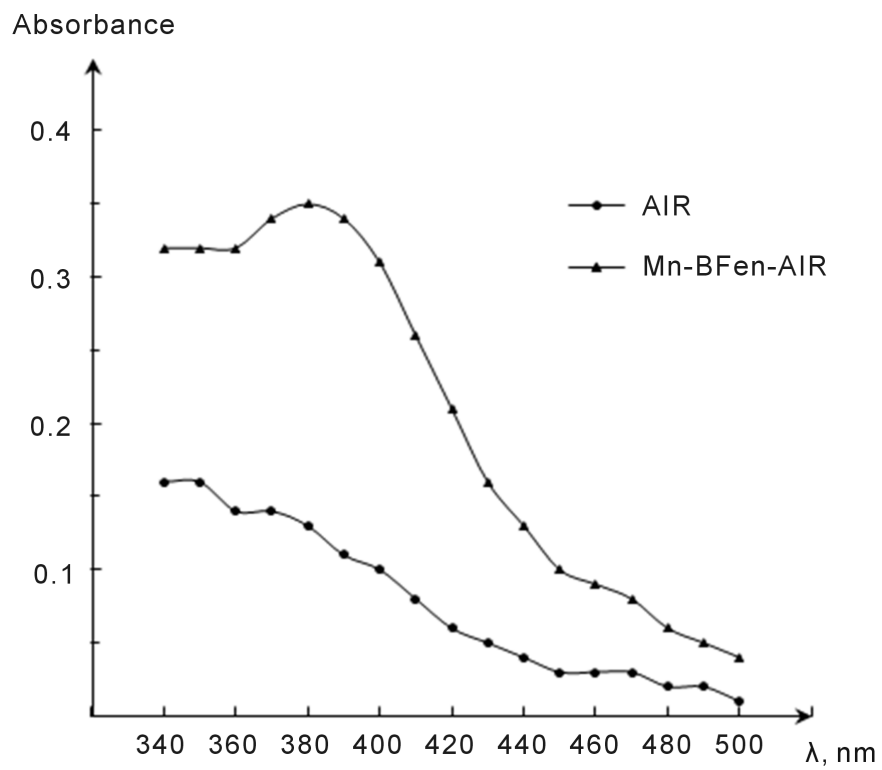

Figure 2. Absorption spectra of extract of $\mathrm{Mn}^{2+}-\mathrm{BPhen}-\mathrm{A} 1 \mathrm{R}$ and $\mathrm{A} 1 \mathrm{R}\left(\mathrm{C}_{\mathrm{Mn}}{ }^{+2}=2.23 \times\right.$ $\left.10^{-5} \mathrm{M}, \mathrm{C}_{\mathrm{BPhen}}=1.2 \times 10^{-4} \mathrm{M}, \mathrm{C}_{\mathrm{A} 1 \mathrm{R}}=1.5 \times 10^{-4} \mathrm{M}, \mathrm{pH}=8.3, \mathrm{C} \Phi-46,1=1 \mathrm{~cm}\right)$.

\subsection{Composition of the Complex}

The stoichiometric coefficients of the complexing were established. The molar ratio $\mathrm{Mn}$ :BPhen:AlR was proved by the method of shear equilibrium and crossing the lines [8]. The results for the light absorption of the extracts at $390 \mathrm{~nm}$ showed that the complex was formed at a ratio $\mathrm{Mn}: \mathrm{BPhen}: \mathrm{AlR}=1: 2: 2$. By the method of V. A. Nazarenko [9] was established that the complexing form of manganese are the ions $\mathrm{Mn}^{2+}$. The same amount of complex two times was extracted consistently and extraction percentage was found: $99.00 \%$.

Extraction percentage was established by two ways. In once the same amount of complex consistently two times was extracted with chloroform, respectively for each time $5 \mathrm{ml}$. And in the second way again the same experiment carried out, but 5 and $7 \mathrm{ml}$ chloroform was used, respectively for first and second extraction process. Both of measurements carried out under the optimum condition. Results were calculated with equations below, accordingly for first and second way.

$$
\mathrm{E} \%=\frac{\left(\Delta A_{1}-\Delta A_{2}\right) \cdot 100 \%}{\Delta A_{1}} \quad \mathrm{E} \%=\frac{V_{1}\left(\Delta A_{1}-\Delta A_{2}\right) \cdot 100 \%}{\Delta A_{2}\left(V_{2}-V_{1}\right)}
$$

Here, E\%-extraction percentage, $\Delta A_{1}$ and $\Delta A_{2}$-extracts absorption, $V_{1}$ and $V_{2}$-extracts volume.

Extraction constant was found as $\mathrm{K}_{\text {ext }}=8.32 \times 10^{14}$ [10], stability constant was found as $\lg \beta_{\mathrm{K}}=7.2 \pm 0.1$ by the method of intersection of curves [8]. For this purpose was used equation below, which latest was used for building of graphical dependency $\lg \beta_{\mathrm{k}}=f(n)$.

$$
\lg \beta_{k}=\frac{C_{k}}{\left(C_{M n}-C_{k}\right)\left(C_{R}-n C_{k}\right)^{n}}
$$


Here, $C_{M n}, C_{k}, C_{R}$-the concentration of manganese, complex and chromogenic reagent, respectively. $n=1,2,3$.

By the method of Komar [8] was found molar absorptivity is $\varepsilon=(2.27 \pm 0.08)$ $\times 10^{4} \mathrm{l} \cdot \mathrm{g}^{-1} \cdot \mathrm{cm}^{-1}$. By repeating the experiment with different amounts of manganese, a calibration curve is prepared. Beer's law is obeyed in the range of 0.5 $23.0 \mu \mathrm{kg}$ manganese (II). Equation of the calibration curve was based to be $\mathrm{A}=$ $0.042 \mathrm{C}+0.06$. Calibration curve are presented in Figure 3 .

The relative standard deviation for 5 determinations with $0.5-1.0-5.0-10.0$ - $20.0 \mu \mathrm{kg}$ of manganese (II) of the method is $\pm(1.50-1.98) \%$. The detection limit of manganese was found as $0.0020 \mu \mathrm{kg} \cdot \mathrm{ml}^{-1}$. Statistical results are presented in Table 1 [11].

In order to assess the usefulness of the proposed method the influence of strange ions on the extraction-photometric determination of manganese was studied. The tolerance of the method of foreign ions was investigated with

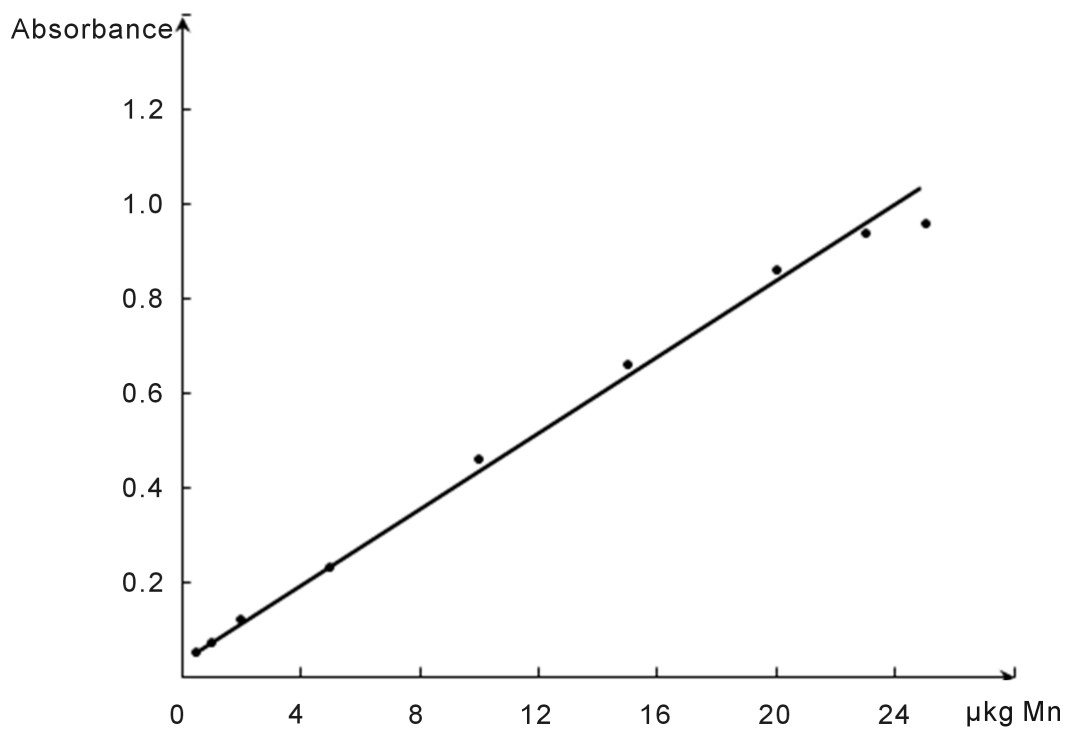

Figure 3. Calibration curve of determination of manganese with Bphen and A1R.

Table 1. Statistical results of determination of manganese with BPhen and AlR ( $n=5, p=$ $0.95)$.

\begin{tabular}{cccccccc}
\hline $\begin{array}{c}\text { Taken } \\
\text { manganese }\end{array}$ & $X$ & $\mathcal{S}^{2} \cdot 10^{3}$ & $S_{X} \cdot 10^{2}$ & $S_{r} \cdot 10^{2}$ & $S_{X} \cdot 10$ & $\frac{\varepsilon \alpha}{X} \cdot 100$ & $\mathrm{X} \pm \varepsilon_{\alpha}$ \\
\hline 1 & 1.01 & 1.52 & 3.89 & 3.87 & 0.17 & 3.91 & $1.01 \pm 0.04$ \\
3 & 3.02 & 2.1 & 4.62 & 1.53 & 0.21 & 1.69 & $3.02 \pm 0.05$ \\
5 & 5.01 & 5.1 & 7.18 & 1.43 & 0.32 & 1.57 & $5.01 \pm 0.08$ \\
9 & 9.02 & 8.2 & 9.04 & 1.00 & 0.40 & 1.09 & $9.02 \pm 0.09$ \\
11 & 11.01 & 6.7 & 8.19 & 0.74 & 0.37 & 0.82 & $11.01 \pm 0.09$ \\
16 & 16.02 & 9.7 & 9.86 & 0.62 & 0.44 & 0.67 & $16.02 \pm 0.10$ \\
20 & 20.03 & 1.9 & 43.2 & 0.22 & 0.19 & 0.23 & $20.03 \pm 0.05$ \\
\hline
\end{tabular}


solutions containing $10 \mu \mathrm{kg} \mathrm{Mn}$ (II) per $25 \mathrm{ml}$ and various amounts of foreign ions. $\mathrm{Mn}$ (II) was determined as $\mathrm{Mn}(\mathrm{BPhen})_{2}(\mathrm{AlR})_{2}$ under the optimum conditions as described in the experimental procedure. The determination of manganese was possible in the presence of $\mathrm{K}$ (I), $\mathrm{Li}$ (I), $\mathrm{Na}$ (I), $\mathrm{Sr}$ (II), Ca (II), Ba (II), Cd (II), Hg (II), Al (III), Ti (IV), Zn (II), V (V), Mo (VI), Cr (III), Ni (II), Pb (II), As (V), Mg (II), Bi (III), In (III), Ge(IV). But Co (II), Zn (II), Cu (II), Fe (III), Ag (I) ions were influenced on the extraction-photometric determination of manganese (II).

\subsection{Determination of Manganese (II) in Eggplant}

$2 \mathrm{~g}$ dried crushed eggplant mass was transferred to the flask with distilled water. For the oxidation of organic part was added concentrated sulfuric and nitric acid. Then was heated a little. The solution was heated in the $450^{\circ} \mathrm{C}-500^{\circ} \mathrm{C}$ temperature during the 10 minute after the completely oxidation of the organic part. Chilled solution was transferred to a $50 \mathrm{ml}$ flask by filtering, then was diluted with the distilled water to the mark. $2 \mathrm{ml}$ aliquot part was transferred to the separatory funnel or test-tube. BPhen and AlR with optimal concentrations was added. Then was diluted by the buffer solution to $10 \mathrm{ml}$ and was extracted with 5 $\mathrm{ml}$ chloroform for 1 minute. Absorbance was measured in СФ 46 in the cuvette of $1 \mathrm{~cm}$ when the phases separated. Amount of manganese was determined from the calibration graph. The results were compared with the results of the determination method of manganese with atom-absorption. Amount of manganese have been determined in eggplant by the proposed method: $173.0 \pm 4.22 \mu \mathrm{g} / \mathrm{kg}$. The proposed system yielded results that compare very well with standart methods. Comparison of methods of manganese is presented in Table 2.

\section{Conclusion}

Although AlR was applied to determine manganese (II) with 1,10-phenantroline, at the first time it was used with 4,7-diphenyl-1,10-phenantroline (BPhen) from heterocyclic diamines, since 1,10-phenantroline containing two phenyl group in the 4 and 7 cases is more sensitive than 1,10-phenantroline. Except this BPhen due to its hydrophobe phenyl groups forms hydrophobe chelates which are well extracted. Due to these reasons the new rapid, simple and sensitive extraction-photometric method of manganese determination with these reagents has been worked out. Feature of the method is applying to determinate of manganese (II) in eggplant by us.

Table 2. Comparison determination methods of manganese with proposed and referenced.

\begin{tabular}{cccc}
\hline $\begin{array}{c}\text { Determination methods of } \\
\text { manganese }\end{array}$ & $\begin{array}{c}\text { Amount of manganese } \\
\mathrm{mg} / \mathrm{kg}\end{array}$ & $\begin{array}{c}\text { Manganese has } \\
\text { been found, mg/kg }\end{array}$ & Deviation \% \\
\hline Proposed method & 180.6 & 173.0 & \pm 4.22 \\
Referenced method & 176.9 & 173.1 & \pm 2.15 \\
\hline
\end{tabular}




\section{Conflicts of Interest}

The authors declare no conflicts of interest regarding the publication of this paper.

\section{References}

[1] Akinci, I. E., Akinci, S. and Yilmaz, K. (2010) Manganese Toxicity on Manganese Accumulation and Mineral Composition of Tomato. Asian Journal of Chemistry, 22, 6991-6997.

[2] Pawar, R.B., Padgaonkar, S.B. and Sawant, A.D. (2001) Spectrophotometric Determination of Manganese (II) by Picolinaldehyde Nicotinoylhydrazone. Indian Journal of Chemical Technology, 8, 200-203.

[3] Zalov, A.Z. (2015) Extraction-Photometric Determination of Manganese (II) with o-Hydroxythiophenol Derivatives and Aminophenols. Vestnik SpbGU, 2, 61-71.

[4] Rehman, F. and Mairaj, S. (2012) Spectrophotometric Determination of Manganese by Biologically Active 2-hydroxy-4-methoxy Acetophenone Oxime. Oriental Journal of Chemistry, 28, 881-885. https://doi.org/10.13005/ojc/280230

[5] Jernocek, A.K. and Talut, I.E. (2003) Analiticheskaya ximiya dlya budushix provizorov. Vol. I, Uchebnoe posobie, Vitebsk, VGMU, 362.

[6] Lavrukhina, A.K. and Yukina, L.V. (1974) Analyitical Chemistry of Manganese, Nauka, Moskow, 315.

[7] Rustamov, N.Kh., Aliyeva, A.A. and Agamaliyeva, M.M. (2003) Azoderivatives of Salicylic Acid in the Presence of o-Phenanthroline as an Extraction Reagent for the Photometric Determination of Fe(III). Azerbaijan Chemical Journal, 2, 54-57.

[8] Bulatov, M.I. and Kalinkin, I.P. (1976) Practical Manual of Photocolorymetric and Spectrophotometric Methods Analysis.

[9] Nazarenko, V.A. (1969) Proceedings of the Committee on Analytical Chemistry. Nauka, Moscow, 12.

[10] Gershuns A.L., Adamovich L.A. and Skorobogatov V.M. (1974) Ekstraktsiyakompleksa $\mathrm{Cu}(\mathrm{II})$ s 2,2'-dixinolinom v prisutstviikislotnixkrasiteley. Journal of Analytical Chemistry, 29, 1905.

[11] Adamovich, L.P. (1960) Ratsionalnie priemi sostavleniya analiticheskix propisey. Izdatelstvo Charkovskogo Universiteta, 17. 